\title{
Influence of Parity on the Fetal Prognosis at the Philippe Maguilen Senghor Health Center (DAKAR): About 37,801 Cases
}

\author{
Diallo $A k^{1,2 *}$, Gueye $M^{1,2}$, Diakhate $A^{1,2}$, Diop $D^{1,2}$, Wade $\mathrm{AM}^{1,2}$, Ndour $\mathrm{SB}^{1,2}$, Niang $\mathrm{N}^{1,2}$, Cisse $\mathrm{A}^{1,2}$ \\ and Mbaye $\mathbf{M}^{1,2}$ \\ ${ }^{1}$ Centre de Santé Philippe Maguilen SENGHOR, Aéroport Yoff, Dakar, Sengal \\ ${ }^{2}$ Clinique Gynécologique et Obstétricale, EPS Aristide Le Dantec, Dakar Auteur, Sengal
}

*Corresponding author: Abdou karim diallo, Centre de Santé Philippe Maguilen SENGHOR, BP: 29026 ou 8951 Aéroport Yoff,

Dakar, Sengal

\section{ARTICLE INFO}

\section{Received: 彗 August 03, 2020 \\ Published: 幽 August 13, 2020}

Citation: Diallo Ak, Gueye M, Diakhate A, Diop D, Wade AM, et al. Influence of Parity on the Fetal Prognosis at the Philippe Maguilen Senghor Health Center (DAKAR): About 37,801 Cases. Biomed J Sci \& Tech Res 29(3)-2020. BJSTR. MS.ID.004818.

Keywords: Fetal prognosis; Primiparity; Large Multiparity

\section{ABSTRACT}

Objectives: To study the influence of parity on the fetal prognosis in the Obstetrics and Gynecology department of the Philippe Maguilen Senghor Health Center between January 1, 2011 and December 31, 2018.

Patients and Method: We carried out a retrospective, descriptive and analytical study. The study framework was the Philippe Maguilen Senghor Health Center (PMSHC) in Yoff (Dakar) and the study period was from January 1, 2011 to December 31, 2018. Our study included all women who had given birth at the PMSHC. The data was compiled from the service's computer database. Data analysis was carried out with Epi info 7.2 software, Excel 2010 and R 3.4.4 software For parameter estimation, the alpha risk error was set at $5 \%$.

Results: Over eight (8) years, 37,801 deliveries were recorded in our structure. The mean age of the patients was 27.34 years +/- 6.23 years. There was $39.11 \%$ of primiparas (PMP) and $11.06 \%$ of large multiparas (LMP). Compared with the fetuses of multiparous patients, fetuses of primiparous patients had 1.09 times $(\mathrm{CI}=[1.00-1.19])$ more risk of prematurity, 1.26 times $(\mathrm{CI}=[1.13-1.40])$ more risk of exceeding term, 1.5 times $(\mathrm{CI}=[1.42-1.59])$ more risk of low birth weight (LBW), 0.44 times $(\mathrm{CI}=0.39-0.50)$ less risk of macrosomia, 0.51 times (CI $=[0.30-0.86])$ less risk of hydramnios, 1.86 times (CI $=[1.28-2.71])$ more risk of oligo-amnios, 1.19 times ( $\mathrm{CI}=[1.01-1.40])$ more risk of in utero fetal death, 1.75 times ( $\mathrm{CI}=[1.64-1.87])$ more risk of having an Apgar score at the 5th minute $<7$. Compared with the fetuses of multiparous patients, fetuses of large multiparous patients had 1.14 times ( $\mathrm{CI}=[1.00-1.30])$ more risk of prematurity, 1.10 times $(\mathrm{CI}=[1.00-1.21])$ more risk of low birth weight, 1.67 times ( $\mathrm{CI}=[1.47-1.89]$ ) more risk of macrosomia, 1.19 times ( $\mathrm{CI}=[1.01-$ 1.40]) more risk of in utero fetal death, 1.14 times ( $\mathrm{CI}=[1.02-1.28])$ more risk to have an Apgar score at the 5th minute $<7$.

Conclusion : Compared with the fetuses of multiparous patients, fetuses of primiparous patients and fetuses of large multiparous patients are at greater risk for certain complications (prematurity, exceeded pregnancy term, LBW, macrosomia, oligo-amnios, in utero fetal death and an Apgar score at the 5th minute $<7$ ). Thus, to improve the fetal prognosis, pregnancies in primiparas and large multiparas require more monitoring.

\section{Introduction}

Although any pregnancy carries risks that can leave sequelae or have a fatal outcome, there are some that carry more risks. Indeed, several studies have shown that compared to multiparas, primiparas and large multiparas have an increased risk of complications 
during pregnancy, labor and delivery and if not properly managed, these complications can lead to an increase in morbidity and mortality in the mother-child pair [1-3]. Despite this, in Senegal, few studies have examined the relationship and nature of fetal complications related to parity. Therefore, in order to overcome this lack of studies on this subject, we conducted a study with the aim of studying the influence of parity on the fetal prognosis in the Obstetrics and Gynecology department of the Philippe Maguilen Senghor Health Center between January 1, 2011 and December 31, 2018.

\section{Patients and Methods}

We carried out a retrospective, descriptive and analytical study. The study framework was the Philippe Maguilen Senghor Health Center (PMSHC) in Yoff (Dakar) and the study period was from January 1, 2011 to December 31, 2018. Our study included all women who had given birth at the PMSHC. The following data were collected:

a) socio-demographic data: age, parity and year of admission;

b) data related to the fetal prognosis: prematurity, hydram- nios, oligoamnios, macrosomia, low birth weight, in utero fetal death and Apgar score.

Data analysis was done using the following softwares: Microsoft Excel, Epi info 7.2 and R 4.3.3. The bivariate analysis allowed us to search for associations between the variables while using the appropriate statistical tests according to their conditions of applicability. The alpha error risk was set at $5 \%$ and the confidence interval at $95 \%$.

\section{Results}

\section{Descriptive Results}

Our study population was 37,801 patients. The mean age of the patients was 27.34 years with a standard deviation of 6.23 years. The extreme ages were 13 years and 53 years with a median of 27 years. There was $39.11 \%$ of primiparas (PMP) and $11.06 \%$ of large multiparas (LMP). The following figure shows the distribution of patients according to parity (Figure 1). The number of admitted patients increased year after year to reach a maximum in 2018 with $19.34 \%$ (or 7,310 patients). The following figure shows the distribution of subjects by year of admission (Figure 2).

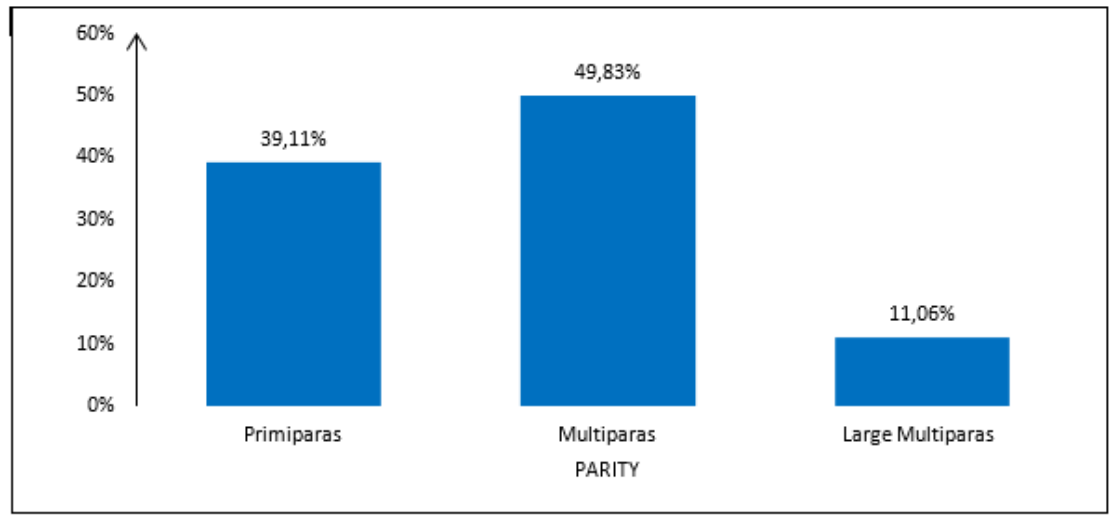

Figure 1: Distribution of patients according to parity. $N=37,801$.

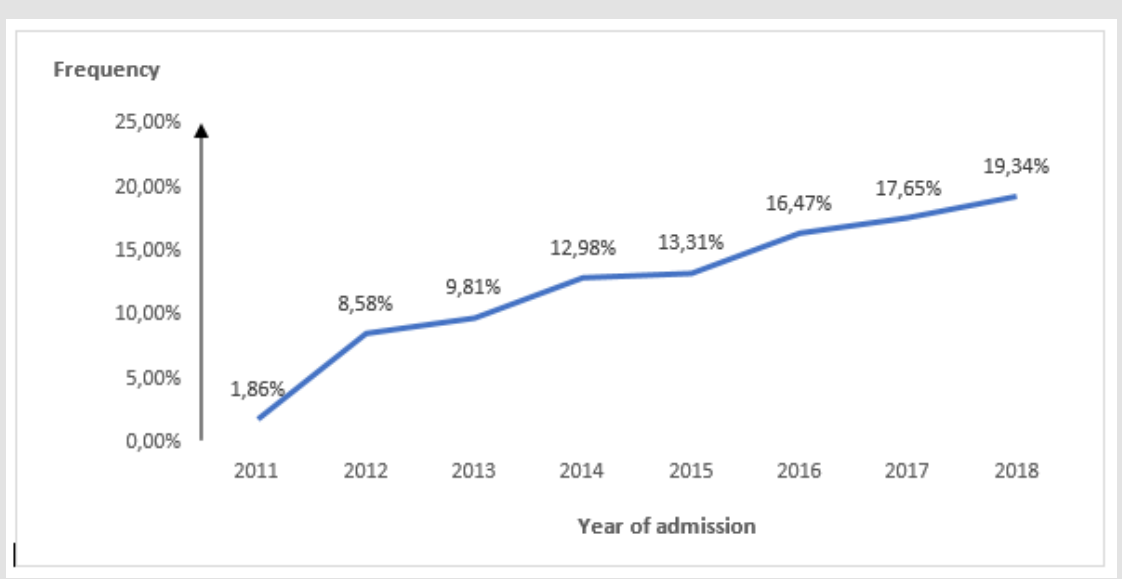

Figure 2: Distribution of subjects by year of admission. $N=37,801$.

\section{Fetal Prognosis}

Prematurity was noted in $7.17 \%$ of primiparas, $6.60 \%$ of multiparas and 7.46 of large multiparas. Exceeded pregnancy term was present in $5.55 \%$ of primiparas, $3.65 \%$ of multiparas and $3.42 \%$ of large multiparas. Low birth weight (LBW) fetus was present in $19.75 \%$ of primiparas, $14.09 \%$ of multiparas and $15.29 \%$ of large 
multiparas. Macrosomia was noted in $2.42 \%$ of primiparas, $5.32 \%$ of multiparas and 8.56 of large multiparas. Hydramnios was present in $0.14 \%$ of primiparas, $0.27 \%$ of multiparas and 0.33 of large multiparas. The proportion of patients who had oligo-amnios was $0.45 \%$ in primiparas, $0.24 \%$ in multiparas and $0.19 \%$ in large multiparas. In-utero fetal death was noticed in $1.90 \%$ of primiparas, $1.60 \%$ of multiparas and $2.08 \%$ of large multiparas. The proportion of patients who had a fetus with a 5 th minute Apgar score $<7$ was $16.09 \%$ in primiparas, $9.87 \%$ in multiparas and 11.12 in large multiparas. A stillborn fetus was present among $3.51 \%$ of primiparas, $3.20 \%$ of multiparas and $4.90 \%$ of large multiparas. Compared with the fetuses of multiparous patients, fetuses of primiparous patients had 1.09 times ( $\mathrm{CI}=[1.00-1.19])$ more risk of prematurity, 1.26 times (CI=[1.13-1.40]) more risk of exceeding term, 1.5 times (CI $=[1.42-1.59])$ more risk of low birth weight, 0.44 times $(\mathrm{CI}=0.39$ 0.50 ) less risk of macrosomia, 0.51 times ( $\mathrm{CI}=[0.30-0.86]$ ) less risk of hydramnios, 1.86 times ( $\mathrm{CI}=[1.28-2.71])$ more risk of oligo-amnios, 1.19 times (CI=[1.01-1.40]) more risk of in utero fetal death, 1.75 times ( $\mathrm{CI}=[1.64-1.87])$ more risk of having an Apgar score at the 5 th minute $<7$.

Compared with the fetuses of multiparous patients, fetuses of large multiparous patients had 1.14 times $(\mathrm{CI}=[1.00-1.30])$ more risk of prematurity, 1.10 times ( $\mathrm{CI}=[1.00-1.21])$ more risk of low birth weight, 1.67 times ( $\mathrm{CI}=[1.47-1.89])$ more risk of macrosomia, 1.19 times $(\mathrm{CI}=[1.01-1.40])$ more risk of in utero fetal death, 1.14 times ( $\mathrm{CI}=[1.02-1.28])$ more risk to have an Apgar score at the 5 th minute $<7$. The differences observed between fetuses of multiparous patients and fetuses of large multiparous patients were not statistically significant for the following variables: exceeded pregnancy term, hydramnios and oligo-amnios. The following table shows the fetal prognosis according to parity (Table 1).

Table I: Fetal prognosis according to parity

\begin{tabular}{|c|c|c|c|}
\hline \multirow{2}{*}{ Fetal morbidity } & \multicolumn{3}{|c|}{ Parity } \\
\hline & PMP, N=14783 & $M, N=18838$ & LMP, N=4180 \\
\hline \multicolumn{4}{|l|}{ Prematurity } \\
\hline $\mathrm{n}$ & 1060 & 1244 & 312 \\
\hline$\%$ & 7.17 & 6.60 & 7.46 \\
\hline OR & $1.09(1-1.19)$ & 1 & $1.14(1-1.3)$ \\
\hline $\mathrm{p}$ & $0.041^{*}$ & & $0.045^{*}$ \\
\hline \multicolumn{4}{|l|}{$\begin{array}{l}\text { Exceeded } \\
\text { pregnancy }\end{array}$} \\
\hline \multicolumn{4}{|l|}{ term } \\
\hline $\mathrm{n}$ & 672 & 687 & 143 \\
\hline$\%$ & 5.55 & 3.65 & 3.42 \\
\hline OR & $1.26(1.13-1.4)$ & & $0.94(0.78-1.12)$ \\
\hline $\mathrm{p}$ & $<0.001^{*}$ & & 0.479 \\
\hline \multicolumn{4}{|l|}{ LBW } \\
\hline $\mathrm{n}$ & 2920 & 2654 & 639 \\
\hline$\%$ & 19.75 & 14.09 & 15.29 \\
\hline OR & $1.5(1.42-1.59)$ & & $1.1(1-1.21)$ \\
\hline
\end{tabular}

\begin{tabular}{|c|c|c|c|}
\hline $\mathrm{p}$ & $<0.001^{*}$ & & $0.045^{*}$ \\
\hline \multicolumn{4}{|c|}{ Macrosomia } \\
\hline $\mathrm{n}$ & 358 & 1002 & 358 \\
\hline$\%$ & 2.42 & 5.32 & 8.56 \\
\hline OR & $0.44(0.39-0.5)$ & & $1.67(1.47-1.89)$ \\
\hline $\mathrm{p}$ & $<0.001^{*}$ & & $<0.001^{*}$ \\
\hline \multicolumn{4}{|c|}{ Hydramnios } \\
\hline $\mathrm{n}$ & 20 & 50 & 14 \\
\hline$\%$ & 0.14 & 0.27 & 0.33 \\
\hline OR & $0.51(0.3-0.86)$ & & $1.26(0.7-2.29)$ \\
\hline $\mathrm{p}$ & $0.011^{*}$ & & 0.441 \\
\hline \multicolumn{4}{|c|}{ Oligoamnios } \\
\hline $\mathrm{n}$ & 67 & 46 & 8 \\
\hline$\%$ & 0.45 & 0.24 & 0.19 \\
\hline OR & $1.86(1.28-2.71)$ & & $0.78(0.37-1.66)$ \\
\hline $\mathrm{p}$ & $0.001^{*}$ & & 0.524 \\
\hline \multicolumn{4}{|c|}{$\begin{array}{c}\text { In utero fetal } \\
\text { death }\end{array}$} \\
\hline $\mathrm{n}$ & 281 & 302 & 87 \\
\hline$\%$ & 1.90 & 1.60 & 2.08 \\
\hline OR & $1.19(1.01-1.4)$ & & $1.3(1.03-1.66)$ \\
\hline $\mathrm{p}$ & $0.038^{*}$ & & $0.03^{*}$ \\
\hline \multicolumn{4}{|c|}{$\begin{array}{c}\text { Apgar's score } \\
<7\end{array}$} \\
\hline $\mathrm{n}$ & 2295 & 1800 & 442 \\
\hline$\%$ & 16.09 & 9.87 & 11.12 \\
\hline OR & $1.75(1.64-1.87)$ & & $1.14(1.02-1.28)$ \\
\hline $\mathrm{p}$ & $<0.001^{*}$ & & $0.018^{*}$ \\
\hline
\end{tabular}

\section{Discussion}

\section{Frequency}

Our study reports a frequency of primiparity of $39.11 \%$. The frequency of women having their first childbirth experience is increasing over time around the world and varies from country to country as the context of each country and society differs. Our frequency is higher than those reported by Okunade [3], Munan [4] and Danish [5] who found frequencies of $15.3 \%, 19.9 \%$ and $27.3 \%$ respectively. On the other hand, it is close to those recorded by other authors: $37.7 \%$ for Ojiyi [1] and $40 \%$ for Latif [6]. The prevalence of $11.06 \%$ for large multiparas found in our study is similar to that reported in Saudi Arabia [7] and Nigeria [8], which are mainly Muslim communities like ours, but it is higher than $2,0 \%$ reported in Lagos [9] where we have a cosmopolitan community with a large Muslim and Christian population. The impact of culture cannot be discounted when considering this topic. Across the Middle East region, India, Pakistan and Africa, large families are highly valued and are a measure of high fertility. In addition, the practice of early marriage and religious beliefs that do not support contraceptive use are considered to be the main issues leading to an increase in the incidence of GMP in these countries $[10,11]$. 


\section{Fetal Prognosis}

The proportion of patients who presented prematurity was higher in large multiparas $(7.46 \%$ against $7.17 \%$ in first-time mothers and $6.60 \%$ in multiparas). The increased frequency of spontaneous premature deliveries in LMPs has also been previously reported by Mgaya [12] and Al Shaikh [7]. On the other hand, low birth weight was more common in first-time mothers (19.75\%) and large multiparas (15.29\%) compared to multiparas (14.09\%). In our study, the risk of prematurity was 1.09 (CI= [1.00-1.19]) in first-time mothers and $1.14(\mathrm{CI}=[1.00-1.3)$ in large multiparas. The birth of a low-weight newborn has been found more frequent in first-time mothers in previous studies $[4,13]$. As for the risk of low birth weight, it was 1.5 ( $\mathrm{CI}=[1.42-1.59])$ in first-time mothers and $1.10(\mathrm{CI}=[1.00-1.21])$ in large multiparas. Our results contrast with the observations of some authors who noted a lower frequency of low birth weight in large multiparas [7,14]. But these two adverse pregnancy outcomes (prematurity and low birth weight) are more likely to be related. Indeed, it should be noted that fetal growth is influenced by other variables such as chronic maternal illnesses, for example: anemia, diabetes and hypertension [15]. Maternal health is another important factor to take into account, a problem that correlates with several adverse pregnancy outcomes.

Recurrent pregnancies and breastfeeding predispose to poor maternal nutrition [16]. These findings, in addition to the high frequency of miscarriage reported by some authors, could be explained by the possible fear of the doctor, but also of the mother, of the loss of the fetus. This may prompt them to perform an early delivery to successfully terminate the pregnancy [7]. The proportion of patients who had a macrosomia fetus was greater in large multiparas $(8.56 \%$ versus $2.42 \%$ in first-time mothers and $5.32 \%$ in multiparas). The risk of fetal macrosomia in large multiparas was 1.67 ( $\mathrm{CI}=[1.47-1.89])$ in our study. Sissoko [17] and Omole-Ohonsi [8] had found risks of $1.28(\mathrm{CI}=[0.93-1.77])$ and $2.27(\mathrm{CI}=[1.72-$ 3.00]) respectively. In our study, oligoamnios was more common in first-time mothers and hydramnios was more common in large multiparas. A study carried out in India also found that first-time mothers were more likely to present with oligo-hydraminos [18].

In our study, primiparas and large multiparas were more likely to have an Apgar score $<7$ at the 5th minute and to have intrauterine fetal death. Other previous studies have objected to similar results $[3,4,17,19]$.

\section{Conclusion}

Compared with the fetuses of multiparous patients, fetuses of primiparous patients and fetuses of large multiparous patients are at greater risk for certain complications (prematurity, exceeded pregnancy term, LBW, macrosomia, oligo-amnios, in utero fetal death and an Apgar score at the 5th minute < 7). Thus to improve the fetal prognosis, pregnancies in primiparas and large multiparas require more monitoring.

\section{References}

1. Ojiyi E, Anozie U, Dike E, Okeudo C, Anolue F, et al. (2012) Pregnancy Outcome In Primigravidae In A Tertiary Hospital: A Three-Year Review 16(1): 5 .

2. Shechter Y, Levy A, Wiznitzer A, Zlotnik A, Sheiner E (2010) Obstetric complications in grand and great grand multiparous women. J Matern-Fetal Neonatal Med Off J Eur Assoc Perinat Med Fed Asia Ocean Perinat Soc Int Soc Perinat Obstet 23(10): 1211-1217.

3. Okunade KS, Okunola H, Oyeneyin L, Habeeb Adeyemi FN (2016) Cross-sectional study on the obstetric performance of primigravidae in a teaching hospital in Lagos, Nigeria. Niger Med J 57(5): 303.

4. Munan R, Kakudji Y, Nsambi J, Mukuku O, Maleya A, et al. (2017) Accouchement chez la primipare à Lubumbashi: pronostic maternel et périnatal. Pan Afr Med J 28: 77.

5. Danish N, Fawad A, Abbasi N (2010) Assessment of pregnancy outcome in primigravida: Comparison between booked and un-booked patients. J Ayub Med Coll Abbottabad JAMC 22: 23-25

6. Latif T, Ali MA, Majeed A, Nahar K, Noor Z (2013) Labor outcome of primigravidae in Mymensingh Medical College Hospital. Mymensingh Med J MMJ 22(3): 432-437.

7. Al Shaikh GK, Ibrahim GH, Fayed AA, Al Mandeel H (2017) Grand multiparity and the possible risk of adverse maternal and neonatal outcomes: a dilemma to be deciphered. BMC Pregnancy Childbirth 17(1): 310.

8. Omole Ohonsi A, Ashimi AO (2011) Grand multiparity: Obstetric performance in Aminu Kano Teaching Hospital, Kano, Nigeria. Niger J Clin Pract 14(1): 6.

9. Ogedengbe OK, Ogunmokun AA (2003) Grandmultiparity in Lagos, Nigeria. Niger Postgrad Med J déc 10(4): 216-219.

10. Rayamajhi R, Thapa M, Pande S (2006) The challenge of grandmultiparity in obstetric practice. Kathmandu Univ Med J KUMJ 4(1): 70-74.

11. Graham W, Woodd S, Byass P, Filippi V, Gon G, et al. (2016) Diversity and divergence: the dynamic burden of poor maternal health. Lancet Lond Engl 388(10056): 2164-2175.

12. Mgaya AH, Massawe SN, Kidanto HL, Mgaya HN (2013) Grand multiparity: is it still a risk in pregnancy? BMC Pregnancy Childbirth 13(1): 241.

13. Ilunga PM, Mukuku O, Mawaw PM, Mutombo AM, Lubala TK, et al. (2016) Fréquence et pronostic néonatal précoce de faible poids de naissance à Lubumbashi, République Démocratique du Congo. Pan Afr Med J 23(232)

14. Shah PS, Knowledge Synthesis Group on Determinants of LBW/PT births (2005) Parity and low birth weight and preterm birth: a systematic review and meta-analyses. Acta Obstet Gynecol Scand. Juill 89(7): 862-875.

15. Aliyu MH, Jolly PE, Ehiri JE, Salihu HM (2005) High parity and adverse birth outcomes: exploring the maze. Birth Berkeley Calif 32(1): 45-59.

16. Teguete I, Maiga AW, Leppert PC (2012) Maternal and neonatal outcomes of grand multiparas over two decades in Mali. Acta Obstet Gynecol Scand 91(5): 580-586.

17. Abdoulaye Sissokho (2013) Parite Et Pronostic De La Gravido-Puerperalite Sur Un Quart De Siecle Dans Deux Hopitaux Universitaires Du District De Bamako. [Mali]: UNIVERSITE DES SCIENCES DES TECHNIQUES ET DES TECHNOLOGIES DE BAMAKO, West Africa.

18. Kaur J, Kaur K (2012) Obstetric complications: Primiparity Vs. Multiparity ID: 5172516.

19. Hashim N, Naqvi S, Khanam M, Jafry HF (2012) Primiparity as an intrapartum obstetric risk factor. JPMA J Pak Med Assoc. juill 62(7): 694-698. 
ISSN: $2574-1241$

DOI: $10.26717 /$ BJSTR.2020.29.004818

Diallo Ak. Biomed J Sci \& Tech Res

(C) This work is licensed under Creative

Submission Link: https://biomedres.us/submit-manuscript.php

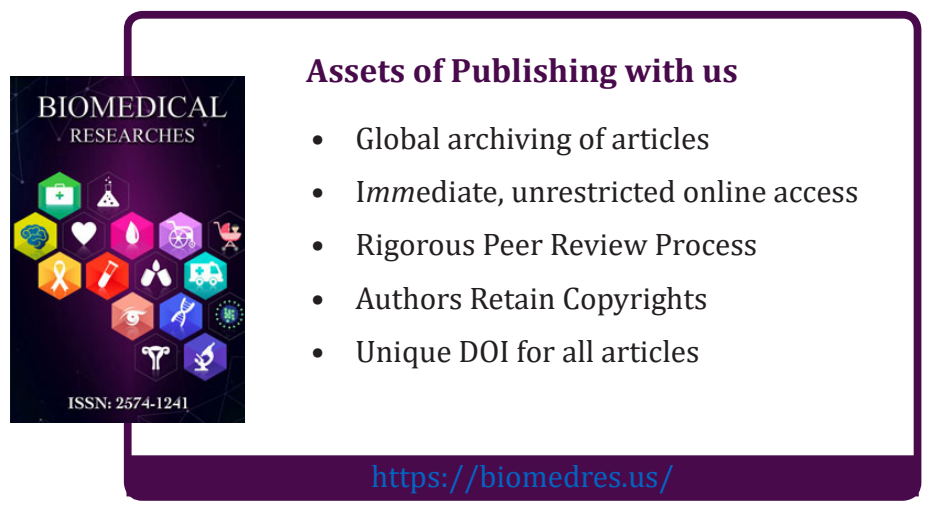

